\title{
Measurements of ice crystal fluxes from the surface at a mountain top site
}

\author{
Waldemar Schledewitch ${ }^{1 *}$, Gary Lloyd ${ }^{1,2}$, Keith Bower ${ }^{1}$, Thomas Choularton ${ }^{1}$, Michael Flynn ${ }^{1}$ and Martin Gallagher ${ }^{1}$ \\ 1 Department of Earth and Environmental Sciences, School of Natural Sciences University of Manchester, M13 9PL
}

2. National Centre for Atmospheric Science, University of Manchester

* Now at Max Planck Institute for Chemistry, Particle Chemistry Department, Mainz, Germany

Correspondence to: Gary Lloyd (gary.lloyd@manchester.ac.uk)

\begin{abstract}
New observations of anomalously high cloud ice crystal concentrations at the Jungfraujoch research station (Switzerland, $3.5 \mathrm{~km}$ a.s.1.) are presented. High-resolution measurements of these ice crystals using a high-speed 2D imaging cloud particle spectrometer confirm that the concentrations far exceed those expected from any known primary ice production mechanisms and are at temperatures well below those for known secondary ice production processes to contribute. A detailed analysis of the cloud ice crystal sizes and habits with respect to wind speed and growth regimes confirms, as hypothesised in previous studies, that their origin is not due to blowing snow or related wind speed influences. As first hypothesised by Vali et al. (Vali et al., 2012) using remote sensing and by Lloyd et al., (2015) with in situ measurements, the most likely explanation is due to a strong surface source generated by the interaction of turbulent deposition of supercooled droplets to fragile ice-

15 covered snow surfaces. This process enhances the detachment of crystal fragments wherein the smaller size mode is turbulently re-suspended even at low wind speeds below expected blowing snow thresholds. These then continue to grow, adding significantly to the ice crystal number concentrations whose size and habit is determined by the transport time between the ice crystal source and measurement location and liquid water profile within the cloud. We confirm, using eddy covariance measurements of ice particle number fluxes, that the likely source is significantly far upwind to preclude flow distortion effects such that the source plume has homogenised by the time they are measured at the mountain top summit.
\end{abstract}

\section{Introduction}

It has been previously reported that very high ice crystal number concentrations can be observed during cloud events in alpine regions (Lloyd et al., 2015). These events cannot be explained by known number concentrations of ice nucleating particles

25 (INPs) and known primary ice mechanisms (e.g. Conen et al. 2015). In some cases the responsible process has been identified as a consequence of so-called secondary ice processes (SIP), such as the Hallet-Mossop process (Hallett et al., 1974) and aeolian generated fragmentation and resuspension of large surface ice particles (blowing snow), Vionnet et al. (Vionnet et al., 2013) and Geerts et al. (2015). In other cases, it was not possible to link high ice number concentrations to these processes mentioned. In this chapter, we attempt use of the well-documented Eddy Covariance (EC) method to differentiate between

30 cloud ice events according to the dominant vertical ice number fluxes to identify the source footprint of the high ice number concentrations that are measured in alpine regions when the clouds are near or in contact with the surface. Although the EC 
method is well developed technical constraints make it difficult to apply in complex terrain and inside a mixed phase cloud with relatively low concentrations of large ice particles to determine cloud particle number fluxes. Nevertheless, we present results from several cases using this approach that strongly suggests the upwind surface was the likely source of these particles,

35 at least in the selected cases. In the first part of the chapter, we describe the instrumentation and methodology used at the Jungfraujoch station where it was applied. The next part explains the Eddy Covariance method used for calculating the fluxes of ice particles. We then provide a critical assessment of the results and their current limitations with a view to highlighting the requirements for more detailed experiments.

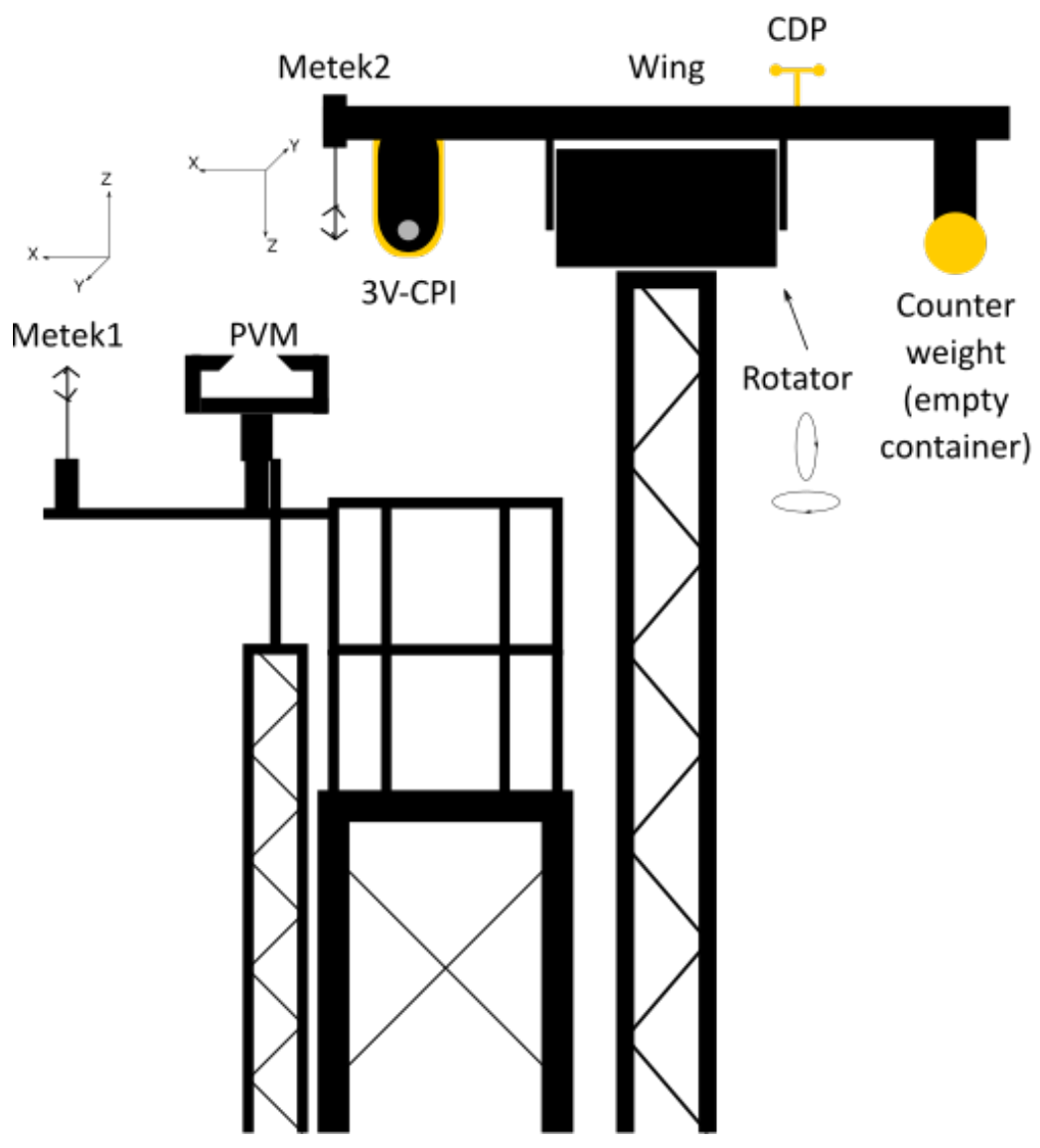

Figure 1 Overview over the instruments (see Table 1) and their position inside the experimental setup. 


\section{Measurement point and methodology}

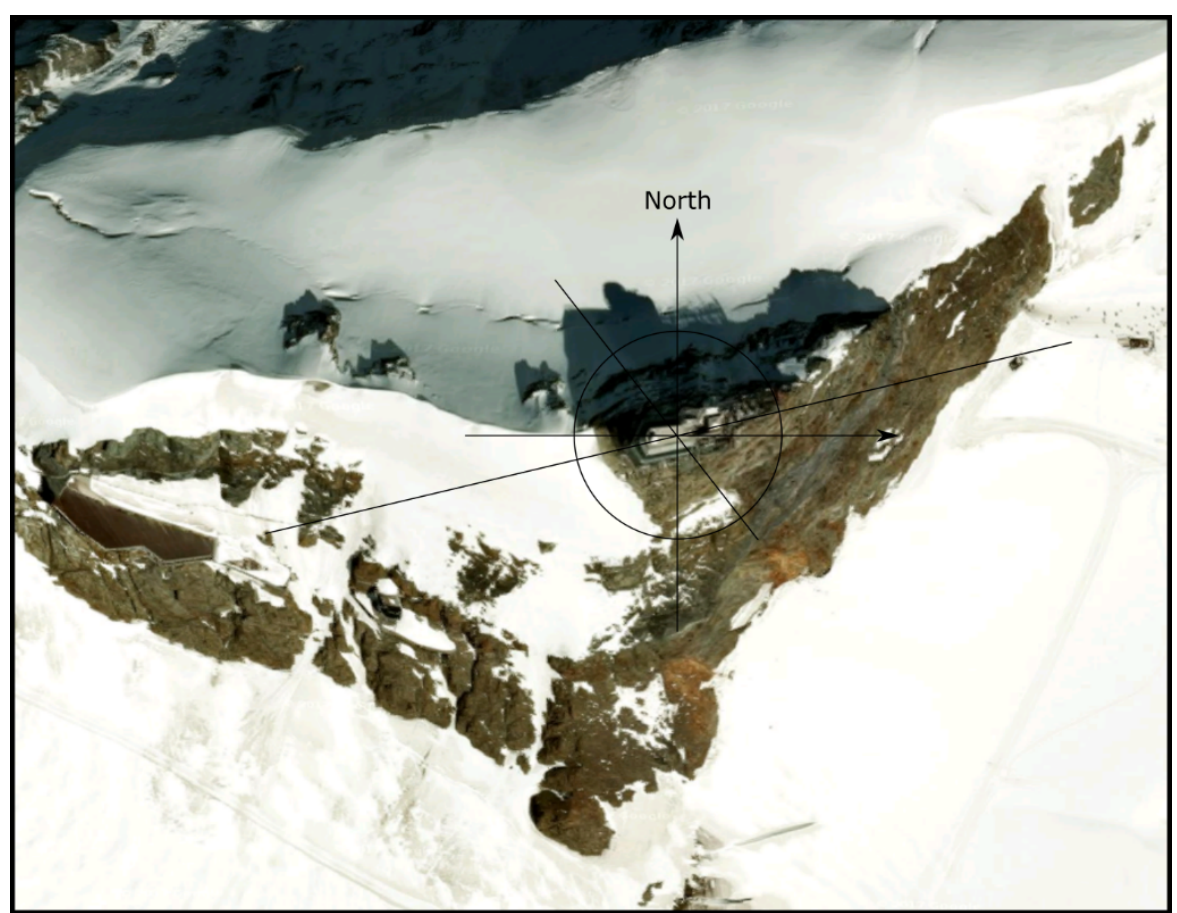

Figure 2 High altitude research station Jungfraujoch seen from above with the Aletschgletscher (Aletsch glacier) to the South.

The Jungfraujoch ridge is located at $3580 \mathrm{~m}$ a.s.l. in the south of Switzerland between the two mountains Jungfrau and Mönch. The research station was selected because of its accessibility, high cloud frequency (37\% per year) and the extensive characterisation of its local aerosol and cloud microphysics prevalent at the site (Baltensperger et al., 1998; Hinz et al., 2005; Lloyd et al., 2015; Hoyle et al., 2016; Kupiszewski et al., 2016) and aerosol composition, CCN and ice nuclei (Choularton et al., 2007; 2016). On a terrace situated on the station roof (see Figure 2), a tower system used for the measurements has been set up as shown in Figure 1. The use of an aero-wing attached to the top of the tower allows for the automated 3D positioning of the attached instruments to orient them into the mean 3D wind vector on a continuous basis. This arrangement has been already successfully used in previous experiments, e.g. the CLoud Aerosol Characterisation Experiments (CLACE) campaigns (Lloyd et al., 2015). For this field campaign the instruments, described in Table 1, have been used and form an EC system to determine cloud particle number fluxes. The 3-View Cloud Particle Imager (3V-CPI) is a hybrid instrument comprising a twodimensional stereoscopic (2D-S, Lawson et al., 2006) shadow imaging spectrometer and a Cloud Particle Imager (CPI, Stratton Park Engineering Company Inc, Boulder Colorado (SPEC)), a charge-coupled device (CCD) imaging spectrometer (3V-CPI Model 2, SPEC Inc.). The use of a 3D sonic anemometer (Metek USA-1, Meteorologische Messtechnik) fixed to the rotating aero-wing next to the inlet of the $3 \mathrm{~V}$-CPI is essential for the flux measurement that connects the fluctuations of vertical wind speed with the change in the number concentration of the measured ice particles over a specific time period. A second Metek sonic anemometer mounted on a separate tower at the same height provided measurements for the alignment of the aero-wing 
with the mean wind vector. It provides the direction of cloud events. The Cloud Droplet Probe (CDP-100, Droplet Measurement Technologies, DMT, Lance et al., 2010), as well as a Particle Volume Monitor (PVM, Gerber Scientific, Inc.) for bulk liquid water content measurement only (Gerber, 1991), provides information about possible contributions from the liquid phase during the measurements. The CDP, PVM and similar cloud spectrometers have been used previously to determine size dependent surface fluxes of cloud droplet number as well as total liquid water to surfaces in complex terrain, (e.g. Beswick et al. 1991, Vong et al. 1995, Kowalski et al. 1997, Klemm et al. 2005, Pryor et al. 2008). Both the CDP and PVM sensors are also known to be sensitive to ice particles, Gerber \& Demott (2014), and as such fluxes from these were not considered here due to uncertainties associated with their lack of ice-liquid discrimination, but rather to quality control total particle number and volume concentrations from the other spectrometers. Vaisala and Rotronics sensors provided measurements of the temperature and the humidity during cloud events.

Table 1 Overview of the instruments that have been used at the Jungfraujoch site and information about measurement type, method, size ranges, and time resolution of the data provided.

\begin{tabular}{|c|c|c|c|c|}
\hline Instrument & Measurement & Method & $\begin{array}{c}\text { Size range } \\
{[\mu \mathrm{m}]}\end{array}$ & $\begin{array}{l}\text { Time } \\
\text { resolution }\end{array}$ \\
\hline $\begin{array}{l}\text { 3V-CPI } \\
\text { combined: } \\
\text { 2D-S \& CPI }\end{array}$ & $\begin{array}{ll}\text { 2D-S: particle size } \\
\text { distributions } & \text { and } \\
\text { shadow imagery } & \\
\text { CPI: particle size } \\
\text { distributions and } \\
\text { particle photographs }\end{array}$ & $\begin{array}{l}\text { 2D-S: optical array probe } \\
\text { (128 element array at } 10 \mu \mathrm{m} \\
\text { effective resolution) } \\
\text { CPI: use of a CCD camera } \\
\text { to photograph particles }\end{array}$ & $\begin{array}{ll}2 \mathrm{D}-\mathrm{S}: & 10- \\
1280 & \\
\text { CPI: } & 2.3- \\
2300 & \end{array}$ & $\begin{array}{l}\text { Single } \\
\text { Particle, } \\
\text { Integration } \\
\text { Period: } 2 \mathrm{D}-\mathrm{S} 1 \\
\text { to }>10 \mathrm{~Hz} \\
\mathrm{CPI} 1 \mathrm{~Hz}\end{array}$ \\
\hline $\begin{array}{l}\text { Metek USA-1 } \\
2 \mathrm{x}\end{array}$ & $\begin{array}{l}\text { Wind components } \mathrm{x}, \\
\mathrm{y}, \quad \mathrm{z}, \quad \text { sonic } \\
\text { temperature }\end{array}$ & $\begin{array}{l}\text { Ultrasonic sound wave } \\
\text { measurement }\end{array}$ & $\begin{array}{l}0-60 \mathrm{~ms}^{-1},-40 \\
\text { to }+70{ }^{\circ} \mathrm{C}, 0.01 \\
\mathrm{~ms}^{-1}, 0.01 \mathrm{~K}\end{array}$ & $30 / 50 \mathrm{~Hz}$ \\
\hline CDP-100 & $\begin{array}{l}\text { Droplet } \\
\text { distribution }\end{array}$ & $\begin{array}{l}\text { The optical diameter of } \\
\text { particles determined } \\
\text { through scattered light }\end{array}$ & 2 to 50 & $1-10 \mathrm{~Hz}$ \\
\hline PVM-300 & Liquid water content & Infrared extinction & 3 to 50 & $1-10 \mathrm{~Hz}$ \\
\hline Vaisala & $\begin{array}{l}\text { Temperature and } \\
\text { humidity }\end{array}$ & & & $\mathrm{Hz}$ \\
\hline
\end{tabular}

\subsection{Processes associated with surface ice crystals}

Under calm and cloudless days, sublimation crystals have been observed to form over snow surfaces in the Antarctic. Gallet et al. (2014) observed during their field studies at Dome $\mathrm{C}$ the rapid growth of long, spiky clustered crystals without noticeable precipitation. The reason behind this phenomenon is the coupled effect between solar radiation and the radiative cooling that 
are responsible for creating a strong temperature gradient in the upper part of the snowfield. This creates a warm point just below the surface (around $1 \mathrm{~cm}$ ). The water vapour originating from this point forms an upward flux that eventually reaches the colder surface and is responsible for a thin region of supersaturation above the surface. This zone of supersaturation is caused by the strong non-linear relationship between the temperature and saturation vapour pressure. In this region, the water vapour freezes and produces part of the crystal-clusters. This way, the sublimation of snow does not lead to a mass loss but to a formation of sublimation crystals. This effect is similar to the production of frost flowers (Style and Worster, 2009) over young sea ice. In contrast to the studies over ice where frost flowers only appear in spots over the ice that provide nucleation sites, the surface of snow provides an endless amount of these nucleation sites. This way, the crystal covered areas can extend over very large areas. The whole process of sublimation crystal production is very sensitive to the density of the snowpack as it alters the thermal profile and hence the release of water vapour. In addition to the mentioned processes, the latent heat shows a diurnal cycle that leads to sublimation of snow during the day and condensation of water vapour from the atmosphere during the night. This condensation process generates surface hoar crystals and further contributes to the formation of crystal clusters. Both processes produce similar crystals that can persist over several weeks before being removed by strong winds.

\subsection{Eddy covariance method}

The eddy covariance (EC) technique provides a direct method of measuring the vertical exchange between the surface and its surrounding (Lee et al., 2005). It has been used to measure the deposition of cloud droplets to hill sites, moorland and forests in sizes up to $15.5 \mu \mathrm{m}$ (Gallagher et al., 1988, 1992 a; b; Beswick et al., 1991; Kowalski et al., 1997; Klemm et al., 2005;

95 Pryor et al., 2008), of fog (Holwerda et al., 2006), and aerosol particles (Schmidt and Klemm, 2008). The original theories have been established under the conditions of stationarity in time and homogeneity in space. These conditions are hardly met in practice and therefore, data quality checking, instrument corrections and coordinate rotation of the wind field must be evaluated to obtain meaningful fluxes. The basis of the EC approach is to define a control volume over a representative, ideally homogeneous, surface footprint, recording the accumulation within it, measure the exchange across all the aerial faces of the volume and infer the surface exchange by the difference. If the turbulent mixing acts as a physical averaging operator, the flow field is effectively one-dimensional, and the flux can be written as

$$
\frac{\overline{\partial \mathbf{c}}}{\partial \mathbf{t}}+\frac{\partial \overline{\mathbf{w c}}}{\partial \mathbf{z}}=\overline{\mathbf{S}} \boldsymbol{\delta}(\mathbf{z})
$$

where $c(t)$ is a generic scalar, $w(t)$ is the vertical component of the velocity vector, the overbar denotes the averaging operation, $\bar{S}$ is the surface flux, $\mathrm{z}$ the vertical or surface normal coordinate, and $\delta(z)$ is the Dirac delta function. If on the one hand there

105 is no accumulation of $c$ over time, the first term on the left-hand side of formula 1 becomes zero (condition of stationarity). Integrating the formula from the ground $z=0$, to the sensor height $h$, taking into account any zero-plane displacement height for momentum transfer, the function reduces to the total covariance of $w(t)$ and $c(t)$ : 


$$
\overline{\boldsymbol{w c}(\boldsymbol{h})}=\overline{\mathrm{S}}
$$

In the end, the total covariance needs to be replaced with the measured eddy flux. The Reynolds decomposition is applied to separate the expectation value of a quantity from its fluctuations with the decomposition written as:

$$
\boldsymbol{X}=\bar{X}+\boldsymbol{X}^{\prime}
$$

With $X$ either $w(t)$ or $c(t)$. The basic formula for the flux calculations is therefore:

$$
\mathbf{S}=\overline{\overline{\mathbf{w}}} \overline{\overline{\mathbf{c}}}+\overline{\mathbf{w}^{\prime} \mathbf{c}^{\prime}}
$$

115

The first term on the right-hand side of equation (4) often gets substituted by 0 . The argument in the literature is that $\bar{w} \rightarrow 0$ for the conditions of stationarity in time and homogeneity in space. As the measurement location in this experiment is atop a ridge with aspect ratios that differ depending on wind direction, equation 4 is the final version and the remaining term is used to test if the corrections made were valid or not. In this experiment the calculations presented are performed on particle optical size ranges $(>50 \mu \mathrm{m})$ discriminated as far as possible by particle shape as a proxy for ice versus water phase. As such there may be significant uncertainties associated with counting statistics based on sample volume limitations and corrections to particle concentrations which need to be carefully addressed.

The next question that has to be addressed is the averaging period. The eddy fluxes need to be calculated over a sufficient period such that any significant contributing eddies can be sampled. On the other hand, the flux can be influenced by meteorological changes rather than the fast turbulent changes, if the averaging time is too long. To address this problem, the ogive presentation of the co-spectrum of the vertical wind component and another property (e.g., sonic temperature) can be used. An ogive shows the cumulative contribution of different eddy scales of increasing importance to the total transport as a point on the ogive plot which is the integral under the spectral density curve between the highest frequency recorded and the frequency of interest. If the curve of the ogive reaches its asymptote, the corresponding time to this frequency represents an adequate flux averaging time. Another important task to address is definition of an appropriate wind coordinate system. Recently, the planar fit coordinate system has been favoured in eddy flux measurements (Wilczak et al., 2001). Unfortunately, this coordinate system cannot be used if the sonic anemometer has been moved frequently as is required to minimise possible instrument inlet sampling issues due to misalignment with the mean flow as in this experiment where the slope flow has a significant non-vertical component. In this experiment the rotating wing, used on the Jungfraujoch to minimise artefacts in particle size distribution measurements arising from instrument inlet alignment, moves every minute into the mean of the wind vector. Therefore, we are able to adopt the natural wind coordinate system forcing the mean lateral and cross wind components to zero without the need for a third rotation as has been used in low wind environments where the vertical component may be 
https://doi.org/10.5194/acp-2022-69

Preprint. Discussion started: 11 February 2022

(c) Author(s) 2022. CC BY 4.0 License.

(c) (1)

significant compared to the horizontal wind components (see Finnigan, 2004). In addition, each periods of coordinate rotation have to be carefully evaluated for (unnatural) over-rotations. A separate fixed 3D sonic anemometer on a parallel tower at the 140 same height is therefore used for quality control of the rotations.

Table 2 Summary of days with significant upward (+) and downward (-) fluxes for particles with a diameter of more than $50 \mu m$.

\begin{tabular}{|c|c|c|c|c|c|c|c|}
\hline Date & Time (UTC) & $\begin{array}{l}\text { Number } \\
\text { of flux } \\
\text { periods } \\
(+/-)\end{array}$ & Direction & $m^{-2} \alpha^{-1}$ & $\begin{array}{c}\text { Particle } \\
\text { concentration } \\
>50 \mu \mathrm{m} \\
\text { median }(\max )\end{array}$ & median & $\begin{array}{c}\text { Wind speed } \\
\text { vertical } \\
\text { median (max) }\end{array}$ \\
\hline & & & & $\mathrm{m}^{-2} \mathrm{~s}^{-1}$ & $1^{-1}$ & ${ }^{\circ} \mathrm{C}$ & $\mathrm{ms}^{-1}$ \\
\hline 26.01 .2017 & $1516-2315$ & $31 / 14$ & South & $-67348-22691$ & $\begin{array}{l}7-572 \\
(1870)\end{array}$ & -16 to -15 & $12-17(26)$ \\
\hline 27.01 .2017 & $0000-1700$ & $4 / 6$ & South & $-7628-11878$ & $0-104(961)$ & -17 to -14 & $10-19(22)$ \\
\hline 30.01 .2017 & 0600-2015 & $18 / 17$ & North & $-24607-35573$ & $\begin{array}{l}1-343 \\
(1916)\end{array}$ & -11 to -8 & $2-9(25)$ \\
\hline 01.02 .2017 & $1508-1545$ & $1 / 1$ & North & $-3337-1439$ & $2-5(251)$ & -10 to -9 & $5-6(17)$ \\
\hline 02.02 .2017 & $0600-1000$ & $5 / 2$ & South & $-2862-1130$ & $0-7(374)$ & -12 to -10 & $4-12(19)$ \\
\hline 03.02 .2017 & 1908-23:59 & $10 / 11$ & $\begin{array}{c}\text { North } \\
\text { (2 South) }\end{array}$ & $-6565-37643$ & $\begin{array}{l}0-121 \\
(1150)\end{array}$ & -16 to -13 & $1-7(16)$ \\
\hline 04.02 .2017 & 0400-23:59 & $36 / 53$ & $\begin{array}{l}\text { South (until } \\
1300 \text { UTC) }\end{array}$ & $\begin{array}{c}-57464- \\
131541\end{array}$ & $\begin{array}{l}0-172 \\
(3445)\end{array}$ & -18 to -11 & $2-14(39)$ \\
\hline 05.02 .2017 & $0500-23: 59$ & $27 / 34$ & North & $-68374-9994$ & $\begin{array}{l}0-407 \\
(2888)\end{array}$ & -15 to -10 & $2-6(21)$ \\
\hline 07.02 .2017 & 0400-23:59 & $42 / 2$ & North & $-46797-1727$ & $\begin{array}{l}1-493 \\
(4718)\end{array}$ & -14 to -10 & $2-5(14)$ \\
\hline 08.02 .2017 & 0015-0116 & $6 / 0$ & North & -2911 & 46 (3999) & -12 & $4(8)$ \\
\hline 09.02.2017 & $0000-1215$ & $3 / 2$ & South & $-3264-2101$ & $0-33(249)$ & -14 to -13 & $7-14(16)$ \\
\hline 10.02 .2017 & $0000-2115$ & $11 / 32$ & South & $-18766-4576$ & $\begin{array}{l}0-532 \\
(1692)\end{array}$ & -17 to -16 & $8-15(37)$ \\
\hline 11.02 .2017 & 0332-0900 & $1 / 2$ & South & $-930-1631$ & $0(126)$ & -13 to -12 & $2-5(12)$ \\
\hline 12.02 .2017 & 0224-0900 & $0 / 35$ & South & $825-15581$ & $14-43(294)$ & -15 to -14 & $11-14(19)$ \\
\hline
\end{tabular}

\section{Campaign and results}

145 For each day of the campaign in 2017 (22.01.2017 - 18.02.2017), fluxes have been calculated, constantly checking whether the first term on the right side of formula (4) is near zero. An ogive test, as already described, established a suitable average 
time of typically 8 minutes for flux calculations. The wind direction has been corrected for two minutes only, as the 3D wing rotates into the mean wind field every minute to ensure correct, unperturbed measurements of the particle number concentration and size distributions. For the concentration, only particles larger $50 \mu \mathrm{m}$ are considered in the calculations of the flux due to uncertainty in particle shape analysis. Shape and sample volume corrections to the optical array probes (OAP) instrument data products (2D-S) are discussed in detail by Crosier et al. (2011) and Korolev (2007) whilst the CCD imaging probe used to quality control the shape analysis interpretation is discussed by Connolly et al. (Connolly et al., 2007). A more recent discussion of the limitations and comparisons between various imaging probes and optical scattering probes, e.g. CDP, are discussed in further detail by O'Shea et al. (2019). However it should be emphasised that many of these discussions are for aircraft based measurements which can be problematic due to much higher sampling speeds leading to increased artefacts such as particle shattering on instrument surfaces e.g. Korolev et al. (Korolev et al., 2013 b) which has led to such instruments being modified to minimise these effects, e.g. Lawson et al. (2011) .
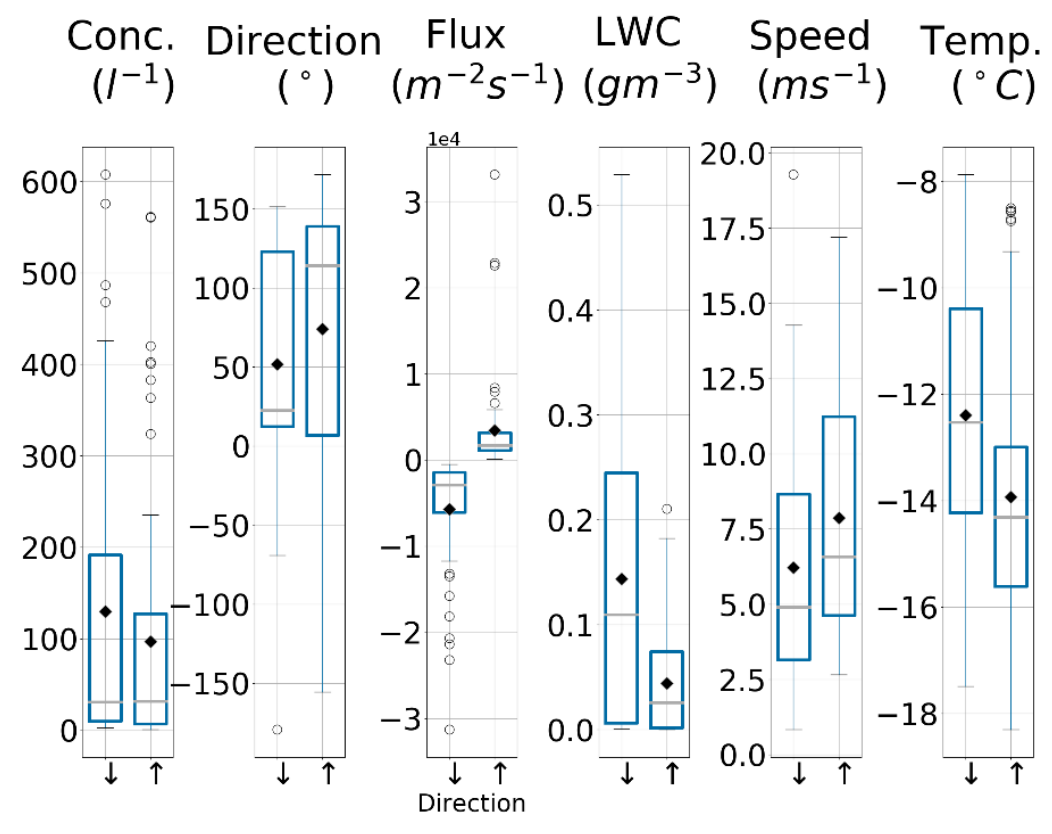

Figure 3 Box plots of the eight-minute fluxes periods for the whole campaign, divided into positive ( $\uparrow$ ) and negative $(\downarrow)$ fluxes. 160 Horizontal lines mark the median; points represent the mean; whiskers mark the most extreme, non-outlier data points; fliers (circles) represent data that extend beyond the whiskers.

To focus the discussion, here we concentrate on periods where significant upward particle fluxes, over 800, or downward fluxes, of less than $-800 \mathrm{~m}^{-2} \mathrm{~s}^{-1}$ are observed ( $20 \%$ of all periods with fluxes larger or smaller than $\left.0 \mathrm{~m}^{-2} \mathrm{~s}^{-1}\right)$. The box plots for all such periods above this threshold (see Figure 3) show median ice number concentrations of about $301^{-1}$ for both, up- and downward fluxes. Hereby, the range of fluxes for downward cases is significantly larger with maximum concentrations of more than $400 \mathrm{l}^{-1}$ observed. Cases with upward fluxes only reach typically half of that value $\left(200 \mathrm{l}^{-1}\right)$ in comparison. Ice number concentrations in cases with negative fluxes occur more often when winds are from the north and vice versa when winds are 
from the south. Downward cases tend to have higher absolute values for the calculated flux $>-10,000 \mathrm{~m}^{-2} \mathrm{~s}^{-1}$ than upward cases $\left(+6,000 \mathrm{~m}^{-2} \mathrm{~s}^{-1}\right)$. Outlying cases with fluxes up to $+-30,000 \mathrm{~m}^{-2} \mathrm{~s}^{-1}$ are often reached during cloud events with an overall enhancement of ice particle concentrations but not out of cloud. The larger liquid water content (LWC, based on CDP data) in downward cases in comparison to upward cases is also seen in the analysis of the CPI images where prevailing water droplets that are larger than $50 \mu \mathrm{m}$ can be seen. These large droplets do not occur in cases with winds from the south and hence for periods with temperatures lower than in northern cases. This is also reflected in the mean wind speeds that are typically greater for southern cases than northern cases.

175 In conclusion, the differences between northern and southern flux cases may be related to the orography of the Jungfraujoch ridge which has a steep and narrow flank in the north down to the base of the mountain with just a few snow covered fetches by comparison with a gently sloped southern fetch dominated mainly by the Aletsch glacier. Only the last $100 \mathrm{~m}$ presented to the station from the southern sector is extremely steep. This difference might lead to the general increase in speed up factor from southern slope. In addition air masses from this fetch experience a longer cooling period than the more rapid, short 180 vertical ascent experience on the northern side. 
large ( $\geq 50 \mu \mathrm{m})$
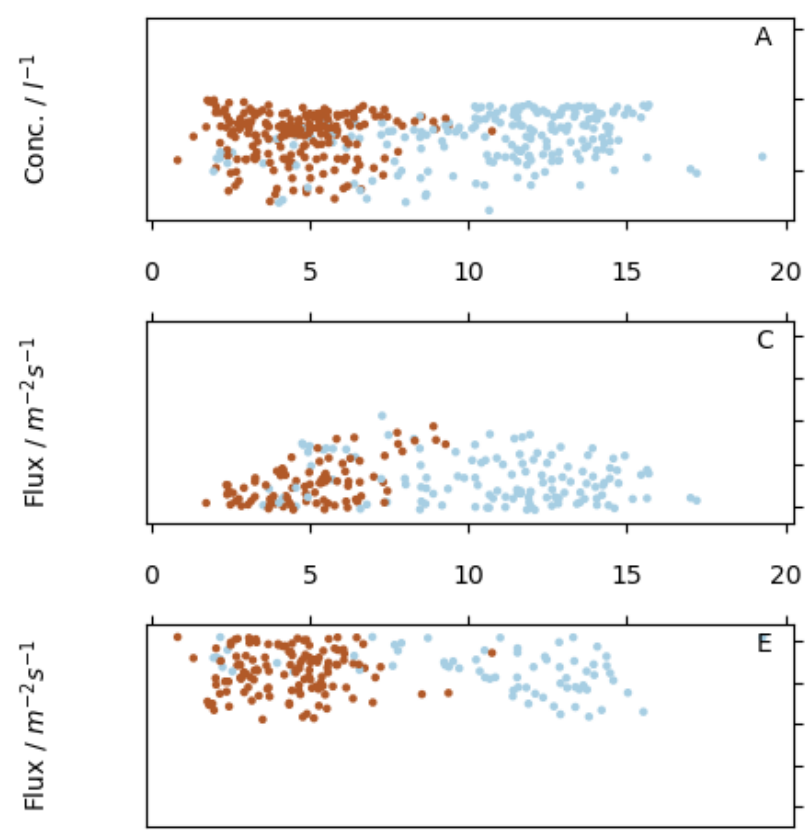

Wind speed $/ \mathrm{ms}^{-1}$
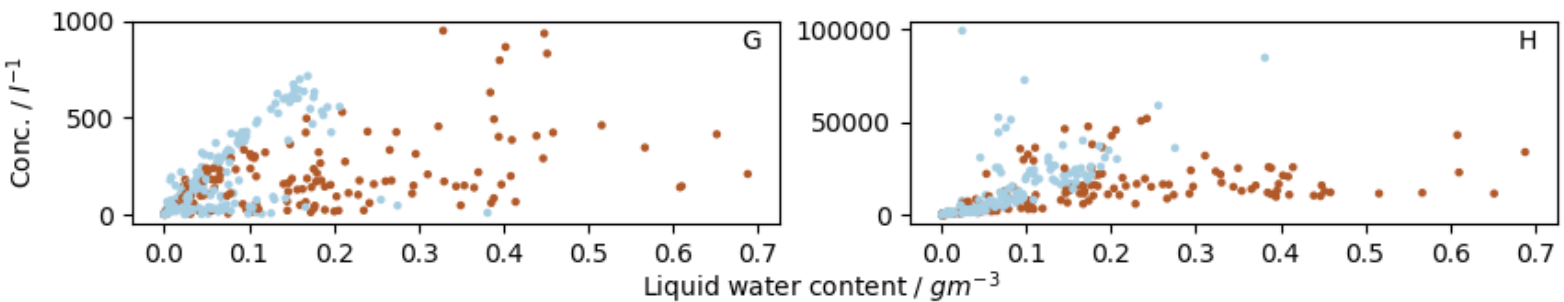

$\frac{1}{3}$
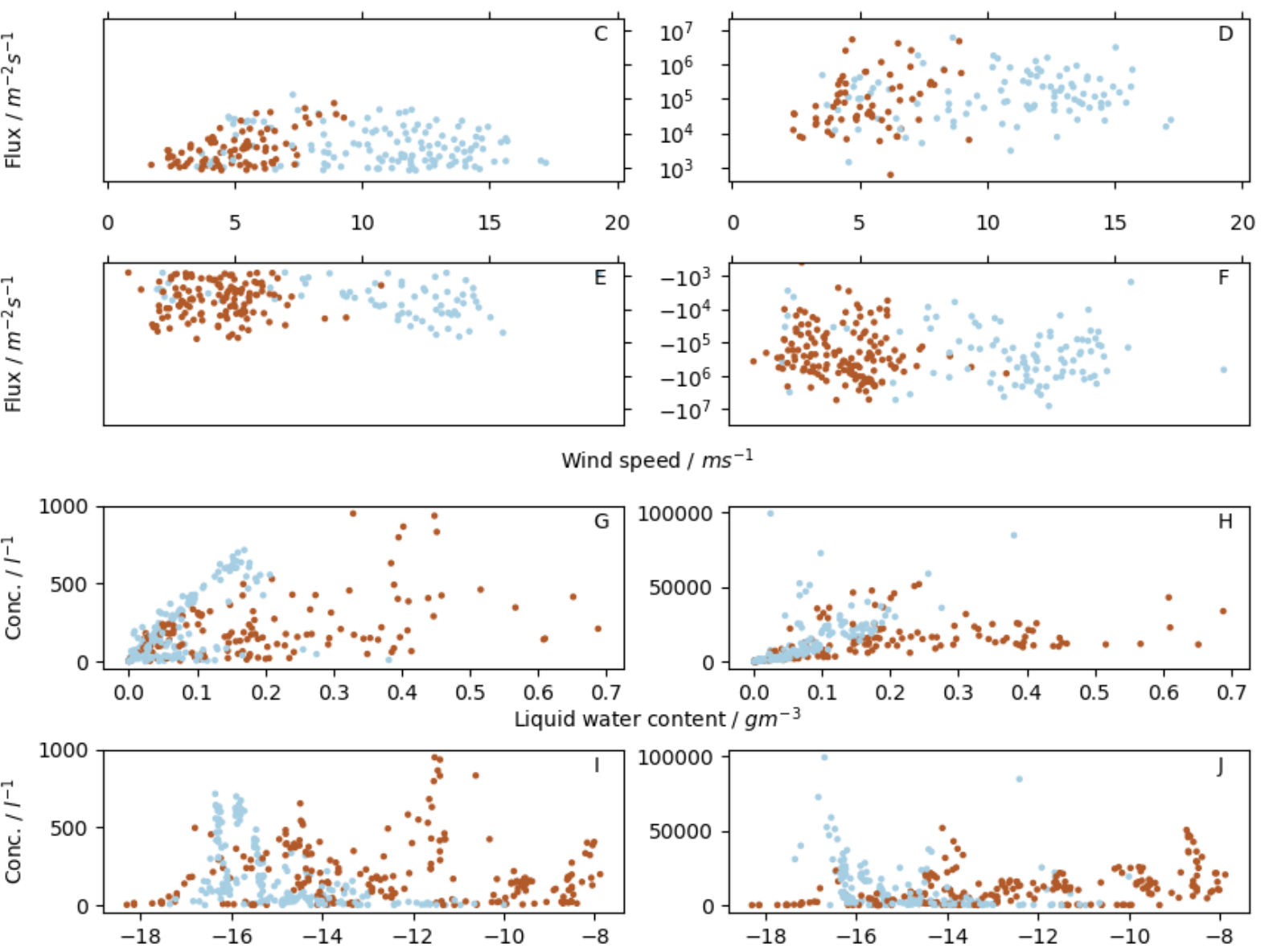

small $(<50 \mu m)$

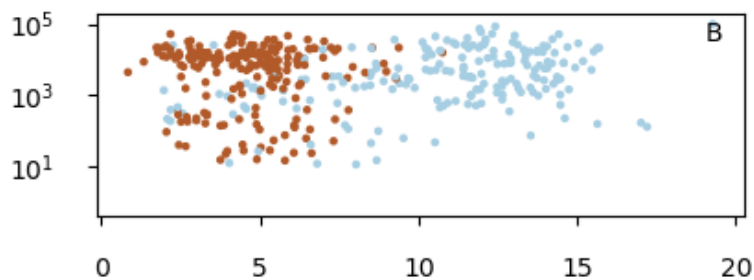

20

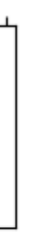


Panel A and B of Figure 4 show the mean concentration of the 8-minute periods used to calculate the flux from. They reveal that there are only 7 out of 213 periods from the north with mean wind speeds larger than $8 \mathrm{~ms}^{-1}$, with maximum concentrations around $10^{3} \mathrm{1}^{-1}$ for particles larger $50 \mu \mathrm{m}$. In contradiction, flux periods from the south cover the whole range of wind speeds up to $20 \mathrm{~ms}^{-1}$. The same observation can be done for particles smaller $50 \mu \mathrm{m}$.

Comparing flux calculations versus wind speed, it appears that there may be a trend with larger upward fluxes with increasing wind speed up to $8 \mathrm{~ms}^{-1}$ for both, northern and southern wind directions (Figure 4, C). A similar relationship does not exist for upward fluxes and downward fluxes (see Table 3), neither for particles smaller $50 \mu \mathrm{m}$ (Figure 4, D) nor for downward fluxes (Figure 4, E-F) despite their size. Hereby, fluxes (upward and downward) of large particles are limited up to $+-10^{-5} \mathrm{~m}^{-2} \mathrm{~s}^{-1}$, while fluxes of small particles reach higher values by two orders of magnitude.

Table 3: Statistics for Graphs $\mathrm{C}-\mathrm{F}$ in Figure 4 - correlation $r$ and corresponding $\mathbf{p}$ value for hypothesis $\mathrm{H}_{0}$ : Flux does not correlate with wind speed. The last column shows the result for rejecting the $\mathrm{H}_{0}$ hypothesis.

\begin{tabular}{|l|l|l|l|}
\hline Flux & Pearson $\mathrm{r}$ & $\mathrm{p}$ value & $\mathrm{p}<\alpha(=0.05)$ \\
\hline Large, up, South & 0.38 & 0.06 & False \\
\hline Large, up, North & 0.42 & $7.76 \mathrm{e}-5$ & True \\
\hline Large, down, South & 0.20 & 0.45 & False \\
\hline Large, down, North & 0.05 & 0.56 & False \\
\hline Small, up, South & 0.33 & 0.11 & False \\
\hline Small, up, North & 0.15 & 0.26 & False \\
\hline Small, down, South & -0.20 & 0.44 & False \\
\hline Small, down, North & -0.16 & 0.05 & False \\
\hline
\end{tabular}

200 Looking at the LWC and concentration (Figure 4, G), a linear correlation seems to exist up to $0.2 \mathrm{gm}^{-3}$ for fluxes coming from the south. Almost no fluxes from the south exist for larger LWC ( 3 out of 196). Two out of 3 are negative fluxes from the $2^{\text {nd }}$ and $9^{\text {th }}$ of February 2017. The size distribution of the downward flux cases looks similar and differ from the positive flux case (see Figure 5). The negative fluxes have a smaller concentration for particles larger $100 \mu \mathrm{m}$. For smaller particles, it seems like there is a peak for the positive flux period in comparison to the negative flux periods. There is also no cut off for larger particles after this maximum and the maximum size for the CDP. Instead, there are particles up to $10^{3} \mathrm{I}^{-1} \mu \mathrm{m}^{-1}$. This can also be seen in the CPI pictures of the 3V-CPI (see Figure 6). Very large particles, such as intact dendrites or fragments of them, plates and particles with no specific structures around $50 \mu \mathrm{m}$ coexist with very small particles, presumably water droplets. As we used $50 \mu \mathrm{m}$ to distinguish water droplets from ice particles to calculate the fluxes from the larger than $50 \mu \mathrm{m}$ ice particles. This is a limitation of the approach used here. Due to technical limitations of the imaging probes and the uncertainties 210 associated with the scattering spectrometers it becomes technically challenging to discriminate water droplets from nonspherical ice particles for particles smaller $50 \mu \mathrm{m}$. This is especially true for the $2 \mathrm{D}$-S part of the $3 \mathrm{~V}$-CPI. The resolution of the $2 \mathrm{D}-\mathrm{S}$, whose data was used to calculate the flux from, is significantly smaller than that of the CPI (10 vs $2.3 \mu \mathrm{m})$, which is 
a general compromise associated with all cloud instruments between sample volume and field of view and hence counting statistics, e.g. the maximum value of the sample volume of the CPI is only $4 \%$ of the $2 \mathrm{D}-\mathrm{S}$ sample volume (Lawson et al.

215 2006). These are the reasons why the data of the 2D-S have been used. Comparing the particle images of the $10^{\text {th }}$ of February with the $2^{\text {nd }}$ and $9^{\text {th }}$ of February (with negative fluxes) shows also larger ice particles but no large dendrite like ones and also plates in case of the $2^{\text {nd }}$ (even double plates) and rimed particles on the $9^{\text {th }}$ of February. Liquid water droplets on the $9^{\text {th }}$ exceeded the $50 \mu \mathrm{m}$ threshold. This way, they may appear as ice particles using the $50 \mu \mathrm{m}$ threshold. This could be the reason for the negative ice particle flux. In reality the situation could be reversed if the liquid water droplets didn't appear in the number concentration of the ice particles. The $10^{\text {th }}$ of February shows rimed ice particles measured at lower temperatures than the negative flux periods on the $2^{\text {nd }}$ and $9^{\text {th }}$ of February. The size distribution (see Figure 5) shows larger concentrations, around one to two orders of magnitude larger at the second peak for larger particles and also a wider spread size distribution. This distribution is not as defined as the one for the negative fluxes. Here, water droplets also existed but smaller than the cut-off threshold of $50 \mu \mathrm{m}$ and therefore do not affect the flux measurement for the larger ice particles.

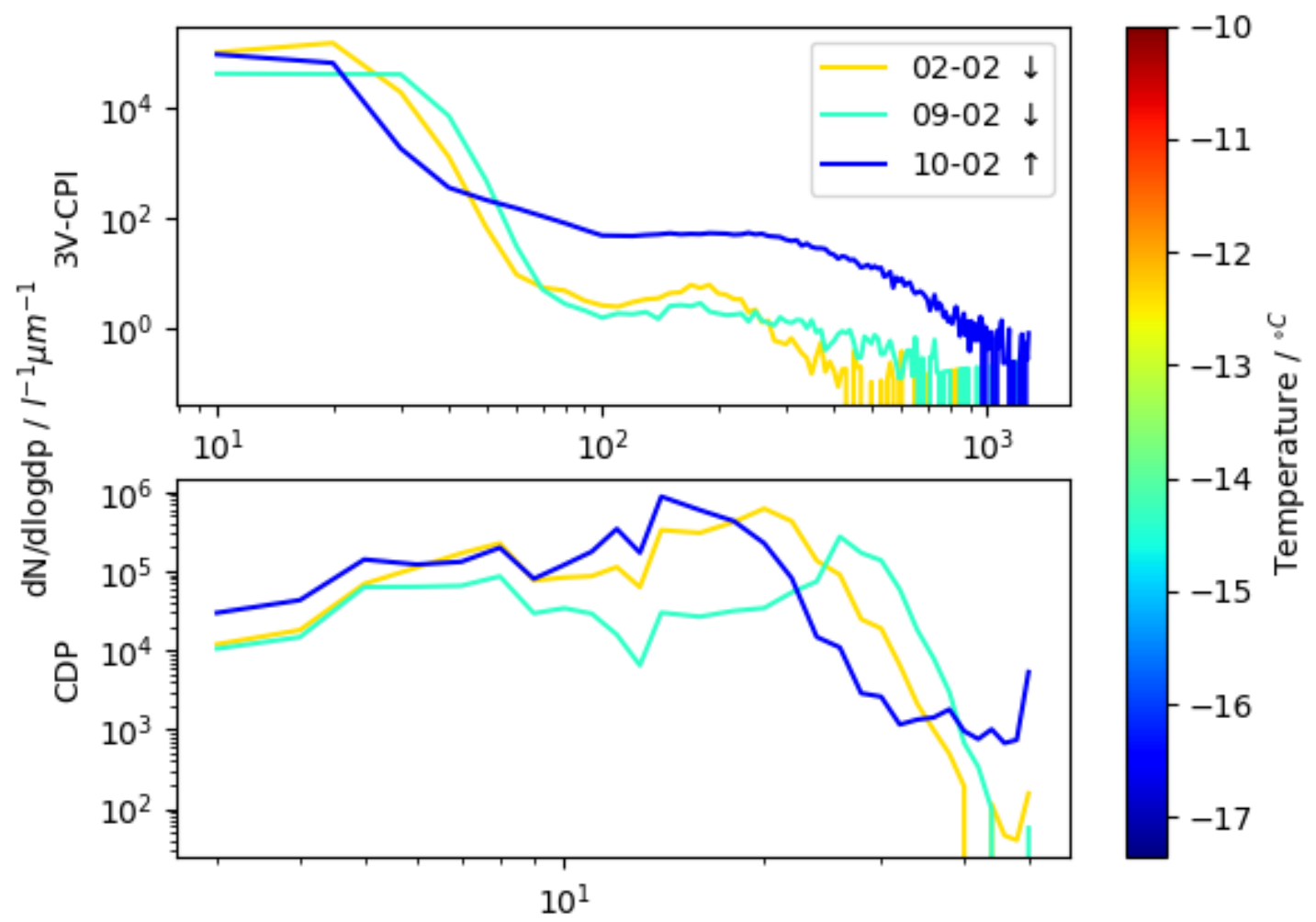

Figure 5 Normalized size distribution of the 3V-CPI and the CDP for all sizes from 2.3 up to $1280 \mu \mathrm{m}$. The colour of the lines indicates the mean temperature during the 9-minute flux from which the flux was calculated (see colour bar). The legend shows the date and the direction of the flux (positive or negative). 
Examining the LWC versus the concentration panels (see Figure 4, G-H), there is enough evidence to conclude there is a significant linear relationship between the LWC and the measured concentration from the South (at least for some cases) as well as for the North (see Table 4). This seems to correspond to the riming effect that not have been ruled out by Rogers \& Vali (1987). More liquid water droplets interact with the surface (snow, stone, and trees) and produce small ice crystals that get lofted into the cloud. This correlation can be seen even more for small particles.

Table 4: Same as Table 3 for panels $G$ and $H$ in Figure 4 but for hypothesis $\mathrm{H}_{0}$ : Concentration does not correlate with LWC.

\begin{tabular}{|l|l|l|l|}
\hline Concentration & Pearson $r$ & $\mathrm{p}$ value & $\mathrm{p}<\alpha(=0.05)$ \\
\hline Large, South & 0.62 & $3.45 \mathrm{e}-22$ & True \\
\hline Large, North & 0.55 & $6.79 \mathrm{e}-14$ & True \\
\hline Small, South & 0.69 & $1.87 \mathrm{e}-28$ & True \\
\hline Small, North & 0.51 & $6.07 \mathrm{e}-12$ & True \\
\hline
\end{tabular}

The concentration versus temperature panels (see Figure 4, I-J) show interesting temperature regions with enhanced ice number concentration of large particles between -15 and $-17{ }^{\circ} \mathrm{C}$ for wind from the south, around $-14,-12$, and $-8{ }^{\circ} \mathrm{C}$ (entering the Hallett-Mossop zone) for wind from the north. Corresponding temperature regions with enhanced ice number concentrations can be found as well for small ice particles but is missing for the region from the north around $-12{ }^{\circ} \mathrm{C}$. These temperature regions occur during at most two different days. More measurements are necessary to investigate if theses temperature regions are an artefact from the measurement technique or if the ice number concentration of large and small particles were influenced by the temperature. 
https://doi.org/10.5194/acp-2022-69

Preprint. Discussion started: 11 February 2022

(c) Author(s) 2022. CC BY 4.0 License.
Atmospheric

Chemistry

and Physics

Discussions

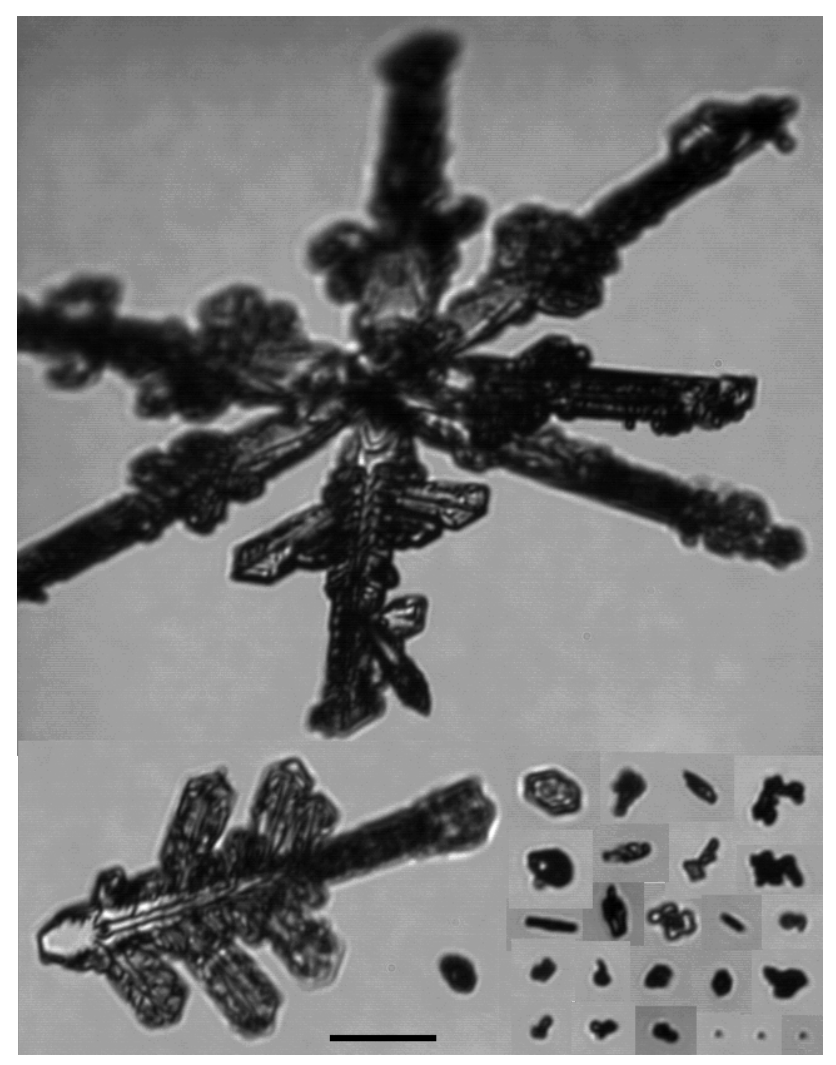

245 Figure 6 CPI images of typical ice particles and water droplets for LWC $>0.21 \mathrm{gm}-3$ for positive flux on the $10^{\text {th }}$ of February. The horizontal scale (bottom of figure) indicates $100 \mu \mathrm{m}$. 
https://doi.org/10.5194/acp-2022-69

Preprint. Discussion started: 11 February 2022

(C) Author(s) 2022. CC BY 4.0 License. \begin{tabular}{l} 
Atmospheric 을 \\
Chemistry \\
and Physics \\
\hline Discussions
\end{tabular}

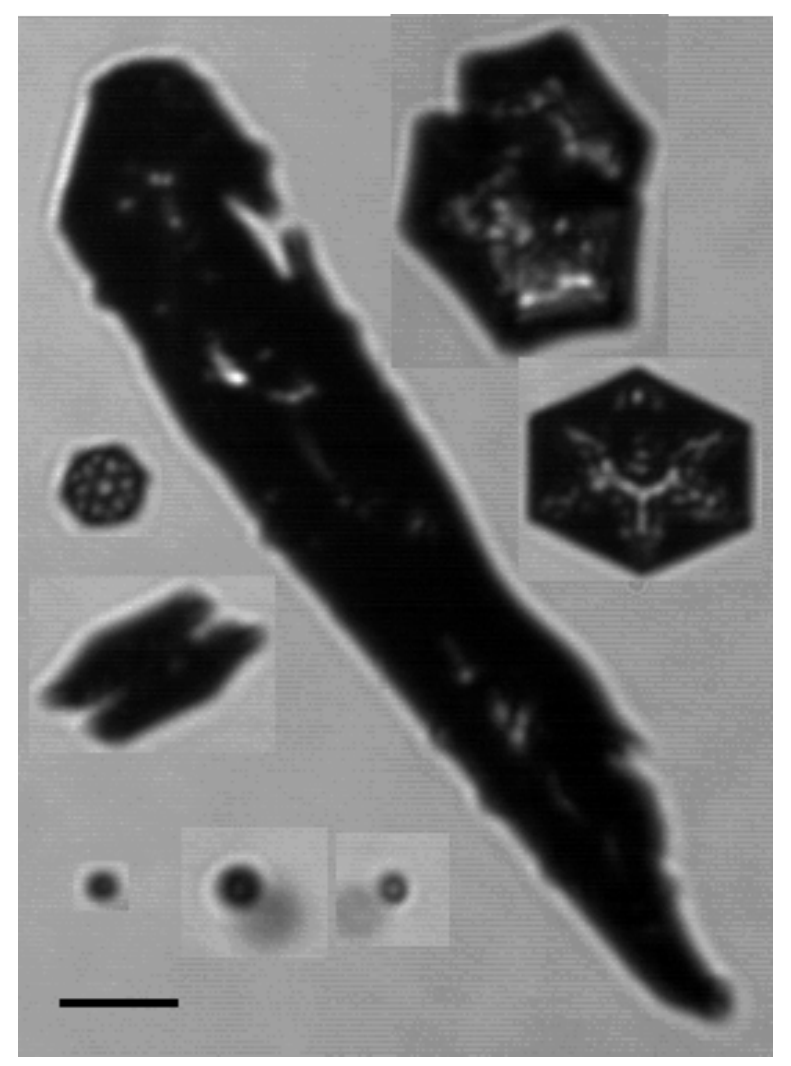

Figure 7 Same as Figure 6 but for the $2^{\text {nd }}$ of February and negative flux. 


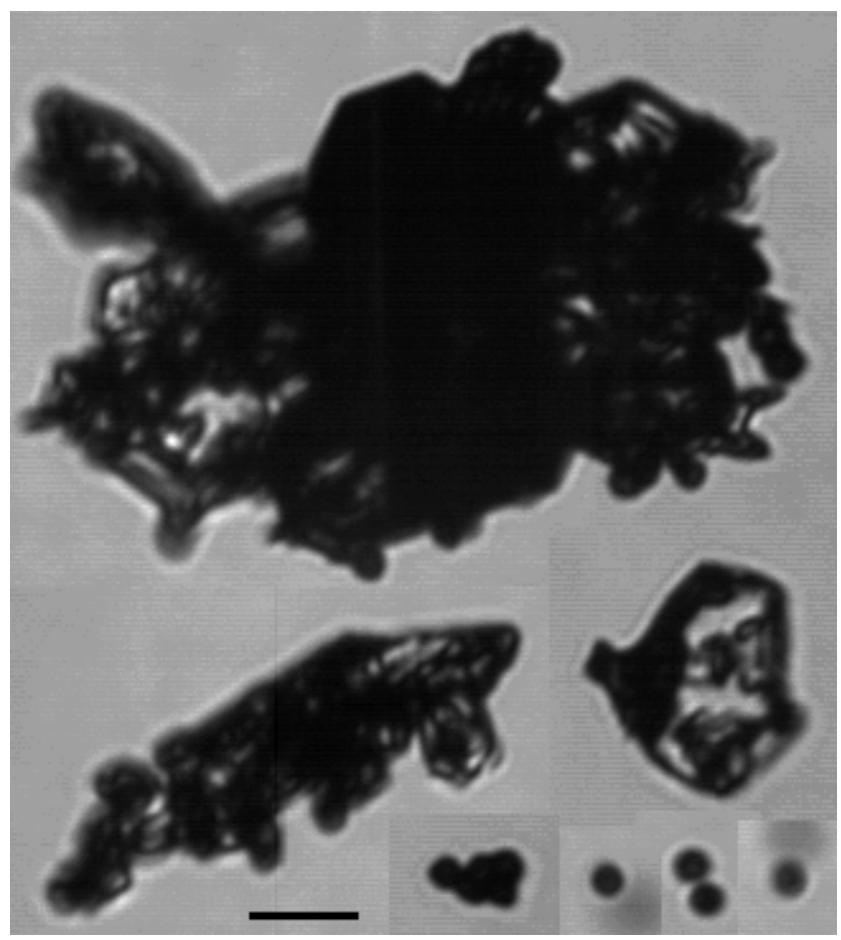

Figure 8 Same as Figure 6 but for the $9^{\text {th }}$ of February and negative flux.

\section{Summary}

- Fluxes can be obtained from measured ice particle number concentrations. In cloud free cases, the most reasonable source is ice particles grown on the surface particularly when the wind speed threshold does not reach values necessary for initiation of blowing snow. CPI images recorded during suspected blowing snow events confirm that the particles are similar to those observed previously during blowing snow events, namely aged particles with rounded edges due to the transport through unsaturated air with respect to ice. Still, the low wind speeds as well as a missing correlation between wind speed and ice number concentration allow us to discard blowing snow as a mechanism for the measured high ice number concentrations. We, therefore conclude that frost crystals growing on the snow surface are thye likely source of the ice crystals following Lloyd et al

- Also, fluxes (with relevant values) do not always occur. It seems that it takes time for the surface source to form and reach a number density sufficient for the wind to begin generating a measurable upward flux. These upward fluxes also have to interact with an orographic cloud near enough to the surface to influence the ice number concentrations inside the cloud. The observed fluxes and conditions in which thy occur are not generally consistent with blowing snow

- In cloud cases indicate strong positive and negative fluxes during an event are present most of the time. CPI images show similar ice particle habits present during each event. This leads to the conclusion that the Jungfraujoch research station remote from the source of the ice particles fluxes so that the air mass sampled at the summit has become well-mixed. 
- Also, the high ice number concentration during cloud events masks the fluxes. On the one hand, downward fluxes of ice particles subdue local upward fluxes from the surface. On the other hand, events from the south produce high liquid water content with larger droplets that have downward motion. Because they are larger than $50 \mu \mathrm{m}$ they are included into the calculation of the large particle fluxes. Hence, they influence the upward fluxes.

- There are cases, with a mixture of up- and downward fluxes but also cases that only present positive or purely negative fluxes. The reason for these cases with one dominant direction from or to the surface has yet to be found.

- The use of a 3D rotating wing is suited for the measurement of ice particles using a closed path shadow imager that normally is located underneath a wing of an airplane that has to be faced parallel to the mean wind field. For future work, we suggest improvements to such setups can include use of open-path cloud instruments as closed path instruments are more prone to shattering, although such artefacts can be removed using inter-particle arrival time analyses. Other potential particle sources, e.g., from above the Jungfraujoch, could be examined using contemporaneous ceilometer measurements along with local cloud base location. Particle concentrations upwind of the station would also confirm the results presented here.

Calculating the fluxes for particles larger $50 \mu \mathrm{m}$ with reasonable high values similar to the values that Farrington et al. (2016) modelled (around $1 \mathrm{e}^{-2} \mathrm{~m}^{-1} \mathrm{~s}^{-1}$ ) strengthens and reaffirm the conclusion from previous publications for the existence of the surface fluxes mechanism. Hereby, it is still dubious if the origin of the upward flux is the growth of surface hoar and sublimation crystals. The riming effect might be an additional possible mechanism as the correlation between LWC and concentration of large but also for small particles suggests as it also happens in the close proximity of the surface. More experiments closer to the origin or in the lab are therefore necessary to reveal more of the mechanism in detail.

\section{Author contribution}

WS, GL, KB, MF made measurements at the mountain top site. WS analysed the data from the campaign and prepared the manuscript. All authors were involved in interpretation of the findings from the campaign.

\section{Acknowledgements}

295 This project was supported by the Natural Environment Research Council under grant NE/1028296/1. We would like to thank the International Foundation High Altitude Research Stations Jungfraujoch and Gornergrat (HFSJG) for providing the support in carrying out experiments at Jungfraujoch and the ACTRIS-TNA project for contributing towards the project infrastructure. We would also like to thank Maria and Urs Otz as well as Joan and Martin Fischer for their help during measurement periods.

\section{References}

Baltensperger, U.; Schwikowski, M.; Jost, D. .; Nyeki, S.; Gäggeler, H. .; Poulida, O., 1998: Scavenging of atmospheric constituents in mixed phase clouds at the high-alpine site jungfraujoch part I. Atmospheric Environment., 32, 3975-3983. Beswick, K. M.; Hargreaves, K. J.; Gallagher, M. W.; Choularton, T. W.; Fowler, D., 1991: Size-resolved measurements of cloud 
Meteorological Society., 117, 623-645.

Choularton, T. W.; Bower, K. N.; Weingartner, E.; Crawford, I.; Coe, H.; Gallagher, M. W.; Flynn, M.; Crosier, J.; Connolly, P.; Targino, A.; Alfarra, M. R.; Baltensperger, U.; Sjogren, S.; Verheggen, B.; Cozic, J.; Gysel, M., 2007: The influence of small aerosol particles on the properties of water and ice clouds. Faraday Discussions., 137, 205-222.

310 Conen, F.; Rodríguez, S.; Hüglin, C.; Henne, S.; Herrmann, E.; Bukowiecki, N.; Alewell, C., 2015: Atmospheric ice nuclei at the high-altitude observatory Jungfraujoch, Switzerland. Tellus, Series B: Chemical and Physical Meteorology., 67.

Connolly, P. J.; Flynn, M. J.; Ulanowski, Z.; Choularton, T. W.; Gallagher, M. W.; Bower, K. N., 2007: Calibration of the cloud particle imager probes using calibration beads and ice crystal analogs: The depth of field. Journal of Atmospheric and Oceanic Technology., 24, 1860-1879.

315 Crosier, J.; Bower, K. N.; Choularton, T. W.; Westbrook, C. D.; Connolly, P. J.; Cui, Z. Q.; Crawford, I. P.; Capes, G. L.; Coe, H.; Dorsey, J. R.; Williams, P. I.; Illingworth, A. J.; Gallagher, M. W.; Blyth, A. M., 2011: Observations of ice multiplication in a weakly convective cell embedded in supercooled mid-level stratus. Atmospheric Chemistry and Physics., 11, $257-273$.

Gallagher, M. W.; Choularton, T. W.; Morse, A. P.; Fowler, D., 1988: Measurements of the size dependence of cloud droplet deposition at a hill site. Quarterly Journal of the Royal Meteorological Society., 114, 1291-1303.

320 Gallagher, M. W.; Beswick, K.; Choularton, T. W.; Coe, H.; Fowler, D.; Hargreaves, K., 1992a: Measurements and modelling of cloudwater deposition to moorland and forests. Environmental Pollution., 75, 97-107.

Gallagher, M. W.; Beswick, K. M.; Choularton, T. W., 1992b: Measurement and modelling of cloudwater deposition to a snowcovered forest canopy. Atmospheric Environment Part A, General Topics., 26, 2893-2903.

Gallet, J. C.; Domine, F.; Savarino, J.; Dumont, M.; Brun, E., 2014: The growth of sublimation crystals and surface hoar on the

Antarctic plateau. Cryosphere., 8, 1205-1215.

Geerts, B.; Pokharel, B.; Kristovich, D. A. R., 2015: Blowing Snow as a Natural Glaciogenic Cloud Seeding Mechanism. Monthly Weather Review., 143, 5017-5033.

Gerber, H.; Demott, P. J., 2014: Response of FSSP-100 and PVM-100A to small ice crystals. Journal of Atmospheric and Oceanic Technology., 31, 2145-2155.

330 Hallett, J.; Mossop, S. C., 1974: Production of secondary ice particles during the riming process. Nature., 249, $26-28$. Hinz, K. P.; Trimborn, A.; Weingartner, E.; Henning, S.; Baltensperger, U.; Spengler, B., 2005: Aerosol single particle composition at the Jungfraujoch. Journal of Aerosol Science., 36, 123-145.

Holwerda, F.; Burkard, R.; Eugster, W.; Scatena, F. N.; Meesters, A. G. C. A.; Bruijnzeel, L. A., 2006: Estimating fog deposition at a Puerto Rican elfin cloud forest site: Comparison of the water budget and eddy covariance methods. Hydrological

335 Processes., 20, 2669-2692.

Hoyle, C. R.; Webster, C. S.; Rieder, H. E.; Nenes, A.; Hammer, E.; Herrmann, E.; Gysel, M.; Bukowiecki, N.; Weingartner, E.; Steinbacher, M.; Baltensperger, U., 2016: Chemical and physical influences on aerosol activation in liquid clouds: a study based on observations from the Jungfraujoch, Switzerland. Atmospheric Chemistry and Physics., 16, 4043-4061.

Klemm, O.; Wrzesinsky, T.; Scheer, C., 2005: Fog water flux at a canopy top: Direct measurement versus one-dimensional

340 model. Atmospheric Environment., 39, 5375-5386.

Korolev, A., 2007: Reconstruction of the sizes of spherical particles from their shadow images. Part I: Theoretical considerations. Journal of Atmospheric and Oceanic Technology., 24, 376-389.

Kowalski, A. S.; Anthoni, P. M.; Vong, R. J.; Delany, A. C.; Maclean, G. D., 1997: Deployment and evaluation of a system for ground-based measurement of cloud liquid water turbulent fluxes. Journal of Atmospheric and Oceanic Technology., 14, 468-

345479.

Kupiszewski, P.; Zanatta, M.; Mertes, S.; Vochezer, P.; Lloyd, G.; Schneider, J.; Schenk, L.; Schnaiter, M.; Baltensperger, U.; Weingartner, E.; Gysel, M., 2016: Ice residual properties in mixed-phase clouds at the high-alpine jungfraujoch site. Journal of Geophysical Research., 121, 12,343-12,362..

Lawson, R. P.; O’Connor, D.; Zmarzly, P.; Weaver, K.; Baker, B.; Mo, Q.; Jonsson, H., 2006: The 2D-S (stereo) probe: Design 350 and preliminary tests of a new airborne, high-speed, high-resolution particle imaging probe. Journal of Atmospheric and Oceanic Technology., 23, 1462-1477.

Lee, X.; Finnigan, J.; Paw U, K. T., 2005: Handbook of Micrometeorology: A Guide for surface flux measurement and analysis. 
Handbook of Micrometeorology. Springer Science + Business Media, Inc., Vol. 29.

Lloyd, G.; Choularton, T. W.; Bower, K. N.; Gallagher, M. W.; Connolly, P. J.; Flynn, M.; Farrington, R.; Crosier, J.; Schlenczek, O.; Fugal, J.; Henneberger, J., 2015: The origins of ice crystals measured in mixed-phase clouds at the high-alpine site Jungfraujoch. Atmospheric Chemistry and Physics., 15, 12953-12969.

O'Shea, S. J.; Crosier, J.; Dorsey, J.; Schledewitz, W.; Crawford, I.; Borrmann, S.; Cotton, R.; Bansemer, A., 2019: Revisiting particle sizing using greyscale optical array probes: Evaluation using laboratory experiments and synthetic data. Atmospheric Measurement Techniques., 12, 3067-3079.

360 Pryor, S. C.; Gallagher, M.; Sievering, H.; Larsen, S. E.; Barthelmie, R. J.; Birsan, F.; Nemitz, E.; Rinne, J.; Kulmala, M.; Grönholm, T.; Taipale, R.; Vesala, T., 2008: A review of measurement and modelling results of particle atmosphere-surface exchange. Tellus, Series B: Chemical and Physical Meteorology., 60 B, 42-75.

Rogers, D. C.; Vali, G., 1987: Ice Crystal Production by Mountain Surfaces. Journal of Climate and Applied Meteorology.

Schmidt, A.; Klemm, O., 2008: Direct determination of highly size-resolved turbulent particle fluxes with the disjunct eddy covariance method and a 12 \&ndash; stage electrical low pressure impactor. Atmospheric Chemistry and Physics Discussions., 8, 8997-9034.

Style, R. W.; Worster, M. G., 2009: Frost flower formation on sea ice and lake ice. Geophysical Research Letters., 36, $20-23$. Vali, G.; Leon, D.; Snider, J. R., 2012: Ground-layer snow clouds. Quarterly Journal of the Royal Meteorological Society., 138, $1507-1525$.

370 Vionnet, V.; Guyomarc'h, G.; Naaim Bouvet, F.; Martin, E.; Durand, Y.; Bellot, H.; Bel, C.; Puglièse, P., 2013: Occurrence of blowing snow events at an alpine site over a 10-year period: Observations and modelling. Advances in Water Resources., 55, 53-63.

Vong, R.; Kowalski, A. S., 1995: Eddy correlation measurements of size-dependent cloud droplet turbulent fluxes to complex terrain. Tellus B., 47, 331-352.

375 Wilczak, J. M.; Oncley, S. P.; Stage, S. A., 2001: Sonic anemometer tilt correction algorithms. Boundary-Layer Meteorology., 99, 127-150.. 